\title{
DESASTRES E DESEMPENHO ECONÔMICO: AVALIAÇÃO DO IMPACTO DO ROMPIMENTO DA BARRAGEM DE MARIANA
}

Lucas Siqueira de Castro ${ }^{1}$

Resumo: Em 2015, ocorreu no Brasil um desastre tecnológico de grandes proporções, o rompimento de uma barragem na cidade de Mariana. Ao serem despejados na bacia do Rio Doce, os detritos de minério geraram externalidades negativas que afetaram dois Estados: Minas Gerais e Espírito Santo. O objetivo deste trabalho é avaliar o impacto do desastre no desempenho econômico desses Estados. Para tanto, foram construídos controles sintéticos visando identificar qual seria o comportamento dos Estados diante da inexistência do desastre. Na produção industrial geral, o Espírito Santo mostrou uma redução de 18,22\%, ao passo que não houve impacto significativo em Minas Gerais. No que tange à produção extrativa mineral, ambos os Estados apresentaram diminuição significativa neste índice em decorrência do desastre, sendo que Espírito Santo teve uma redução de 25,01\%, ao passo que Minas Gerais apresentou uma diminuição de 15,58\%.

Palavras-chave: Desastre Tecnológico. Mariana. Controle Sintético. Desempenho Econômico.

\section{DISASTERS AND ECONOMIC PERFORMANCE: EVALUATION OF THE IMPACT OF THE BREAKING OF THE MARIANA DAM}

\begin{abstract}
In 2015, a major technological disaster occurred in Brazil: The breakdown of a dam in the city of Mariana. When discharged along the Rio Doce basin, the ore debris have generated negative externalities that affected two states: Minas Gerais and Espírito Santo. The objective of this work is to evaluate the impact of the disaster on the economic performance of these States. To this end, synthetic controls were constructed to identify the behavior of the States in the absence of the disaster. In terms of the general manufacturing production, Espírito Santo State had a reduction in $18.22 \%$ in comparison with the situation before the disaster, whereas there was no significant impact in Minas Gerais. As for the extractive mineral manufacturing production, both states showed significant decrease of this index as a result of the disaster: Espírito Santo state had a reduction in $25,01 \%$, whereas Minas Gerais exhibited a decrease in $15,58 \%$.
\end{abstract}

Keywords: Technological Disaster. Mariana. Synthetic Control. Economic Performance.

\section{DESASTRES Y DESEMPEÑO ECONÓMICO: EVALUACIÓN DEL IMPACTO DEL ROMPIMENTO DE LA PRESA DE MARIANA}

Resumen: En 2015, ocurrió en Brasil un desastre tecnológico de grandes proporciones, el rompimiento de una presa en la ciudad de Mariana. Al ser arrojados en la cuenca del Río Dulce, los desechos de mineral generaron externalidades negativas que afectaron a dos Estados: Minas Gerais y Espírito Santo. El objetivo de este trabajo es evaluar el impacto del desastre en el desempeño económico de esos Estados. Para ello, se construyeron controles sintéticos para identificar cuál sería el

\footnotetext{
${ }^{1}$ Universidade Federal Rural do Rio de Janeiro (UFRRJ), Departamento de Ciências Econômicas, Seropédica, Brasil, lucancastro@hotmail.com, http://orcid.org/0000-0002-1006-2702

2 Universidade Federal de Juiz de Fora (UFJF), Departamento de Ciências Econômicas, Juiz de Fora, Brasil, edualmei@gmail.com, http://orcid.org/0000-0003-0045-1672
} 
comportamiento de los Estados ante la inexistencia del desastre. En la producción industrial general, el Espírito Santo mostró una reducción del 18,22\%, mientras que no hubo impacto significativo en Minas Gerais. En lo que se refiere a la producción extractiva mineral, ambos Estados presentaron una disminución significativa en este índice como consecuencia del desastre, siendo que Espírito Santo tuvo una reducción del 25,01\%, mientras que Minas Gerais presentó una disminución del 15,58\%.

Palabras-clave: Desastre Tecnológico. Mariana. Control Sintético. Desempeño Económico.

\section{Introdução}

Por apresentar um cenário de dimensões continentais, com aproximadamente 8,5 milhões $\mathrm{km}^{2}$ de terras, 7.367 km de litoral banhado pelo Oceano Atlântico e 205 milhões de habitantes, o Brasil mostra-se bastante suscetível à ocorrência de desastres de diferentes origens, intensidades e evoluções (IBGE, 2016).

Desastres podem ser definidos, de acordo com o Banco de Dados Internacional de Desastres (The International Disaster Database: EM - DAT), como situações ou eventos que ocorrem de maneira abrupta e que provocam grandes danos, destruição e sofrimento ao ambiente e à população em seu entorno. Embora causado muitas das vezes por forças originadas da natureza, os desastres também podem ser originados de atividades humanas (EM - DAT, 2016).

Normalmente os desastres podem ser classificados de três formas diferentes: quanto à origem, à intensidade e à evolução. Avaliando as formas de origem, os desastres são divididos em dois grandes grupos, os de origens naturais e os tecnológicos. Entre os desastres naturais, têm-se os tipos: geofísicos, meteorológicos, hidrológicos, climatológicos, biológicos, e os "extraterrestres" (extraterrestrial) ou siderais. Por sua vez, os tipos de desastres tecnológicos relacionam-se às substâncias radioativas, a produtos perigosos, a incêndios urbanos, a obras civis (industriais) e ao transporte de passageiros e cargas não perigosas (BRASIL, 2016).

Em termos de intensidade, a Política Nacional de Defesa Civil (PNDC) considera que os desastres podem ser dados nas formas de acidentes, desastres de médio porte, desastres de grande porte e desastres de muito grande porte. Já a evolução aponta que os desastres podem ser considerados súbitos ou de evolução 
aguda, de evolução crônica e gradual, e como resultados da soma de vários efeitos parciais (PNDC, 2007, p. 37-41).

Registros em trabalhos, como os de Bloom e Khanna (2007) e Leiserowitz (2012) mostram que a frequência, bem como a intensidade e o alcance dos desastres veem aumentando ao longo do tempo. Informações do EM - DAT apontaram que, a partir de 1900 até o ano de 2015, foram registrados 21.967 desastres nos cinco continentes do mundo, resultando em 32.948.462 óbitos e afetando 7.311.666.942 de pessoas. Destes, 13.776 (62,71\%) foram considerados naturais e 8.191 (37,29\%) tecnológicos (EM - DAT, 2016).

Nesse mesmo período no Brasil, ocorreram 375 desastres, entre os quais, 219 foram classificados como naturais e 156 como tecnológicos. Ao todo, tais desastres implicaram em 18.977 óbitos e afetaram 105.917.906 indivíduos (EM - DAT, 2016).

Entre os desastres tecnológicos registrados, o mais recente ocorreu em novembro de 2015, sendo considerado de grandes proporções pela Defesa Civil. O excesso no acúmulo de rejeitos de mineração fez com que houvesse o rompimento de uma barragem localizada no município de Mariana, no Estado de Minas Gerais. As externalidades negativas geradas pelo desastre também afetaram o Espírito Santo, uma vez que os detritos se dispersaram ao longo da bacia hidrográfica do Rio Doce.

$\mathrm{Na}$ literatura, sob a ótica qualitativa, existem alguns trabalhos que oferecem visões gerais acerca de perspectivas econômicas $(\mathrm{HORWICH}, 2000)$, sociais e ambientais (MATA-LIMA et al., 2013) ou mesmo dos métodos comumente trabalhados na análise de desastres (OKUYAMA, 2008).

Tratando-se de abordagens quantitativas, há trabalhos que utilizaram modelagem por equilíbrio geral: para analisar o impacto de terremotos na Turquia (SELUCK e YELDAN, 2001); desastres naturais em variados países (OKUYAMA e SAHIN, 2009); alagamentos na cidade de São Paulo (HADDAD e TEIXEIRA, 2014); e o próprio rompimento da barragem de Mariana (SIMONATO, 2017). O enfoque econométrico, por sua vez, compilou trabalhos, em sua maioria com dados em painel, que estudaram desastres naturais em variados países (KAHN, 2004; LOAYZA et al., 2009; NOY, 2009; GUO et al., 2015). Entretanto, há também trabalhos que utilizaram a técnica de controle sintético visando identificar qual seria o comportamento de seus 
ambientes de estudo diante da inexistência dos desastres naturais ocorridos: seja como análise de eficiência das políticas públicas implementadas pelos governos no combate aos desastres (CAVALLO et al., 2010); ou na estimação do custo econômico do excesso de chuvas ocorrido no Estado de Santa Catarina, no ano de 2008 (RIBEIRO, et al., 2014).

Em resumo, percebe-se pela revisão da literatura selecionada que os trabalhos incorporam, em sua grande maioria, apenas a análise dos desastres naturais sobre o crescimento econômico. Desta maneira, o presente artigo tem o objetivo de avaliar o impacto do desastre tecnológico de Mariana no desempenho econômico de Minas Gerais e do Espírito Santo, medido pela trajetória de sua produção industrial e extrativa mineral, adotando a técnica de controle sintético. Por meio desta técnica, serão comparadas as perspectivas da ocorrência do desastre de Mariana contra uma situação de continuidade do ciclo econômico, ou seja, sem a ocorrência do desastre, dada a construção de Minas Gerais e Espírito Santo sintéticos.

Além desta introdução, o trabalho apresenta mais quatro seções. Na próxima seção, são expostos detalhes sobre o rompimento da barragem de Mariana. A terceira seção traça a estratégia empírica perseguida para avaliar o impacto do desastre tecnológico. A quarta seção discute os resultados obtidos. Por fim, a quinta seção reúne as considerações finais.

\section{O Desastre de Mariana}

Na visão do World Bank e da United Nations (2010), os desastres expõem consequências de decisões tomadas por indivíduos: sejam estas relacionadas ao planejamento territorial, à forma como são investidos recursos em programas educativos, ao combate à pobreza, à integração social, dentre outras situações. Desta forma, a ocorrência de fenômenos, associada à maneira como são tomadas as decisões pela população, acabam por convergir em diferentes impactos socioeconômicos e ambientais.

Atividades ligadas à mineração, por exemplo, caracterizam um importante segmento econômico brasileiro. Em função da legislação ambiental vigente, 
barragens de rejeitos estão sendo constantemente construídas no país, o que implica em decisões acerca do planejamento territorial (CBDB, 2011). No Brasil existem cerca de 660 barragens cadastradas com a função de conter rejeitos de mineração, dentre as quais 315 localizam-se no Estado de Minas Gerais (CTPNSB, 2016).

Acidentes com barragens de rejeitos penalizam não só o setor da mineração e a indústria, como também a sociedade e o meio ambiente. Além de acidentes, muitas das vezes também ocorrem incidentes, em que não há a ruptura da barragem, mas implicam no vazamento de sólidos. De acordo com o Comitê Brasileiro de Barragens (CBDB), as causas dos acidentes e dos incidentes são dadas, em grande parte, por falhas de proprietários e operadores das barragens na adoção de procedimentos de segurança para a redução de riscos, uma vez que tais falhas encontram soluções tecnológicas disponíveis (CBDB, 2011).

Pertencente ao Complexo Minerador Germano-Alegria ${ }^{3}$ e recebendo rejeitos provenientes do processo de extração de minério de ferro pela mineradora Samarco $\mathrm{S} / \mathrm{A}$, a barragem de Fundão, até então tida como baixo potencial de risco, pelo cadastro nacional de barragens de mineração, entrou em colapso e rompeu-se no dia 05/11/2015 (DNPM, 2016). Com a ruptura, aproximadamente 34 milhões de metros cúbicos ( $70 \%$ de sua capacidade) de rejeitos de mineração, água e lama foram despejados causando diversos impactos socioeconômicos e ambientais na bacia do rio Doce (ANA, 2016).

Os rejeitos e detritos seguiram os cursos do córrego Santarém e dos rios Gualaxo do Norte e do Carmo por cerca de $77 \mathrm{~km}$, até alcançar o rio Doce. O Instituto Brasileiro do Meio Ambiente e dos Recursos Naturais Renováveis (IBAMA) estima que, apenas neste trecho, foram atingidos 1.500 hectares. Ao todo, como pode ser visto na Figura 1, os dejetos percorreram uma extensão de $663,2 \mathrm{~km}$ até a foz do Rio Doce no oceano Atlântico, localizada na cidade de Linhares, no Espírito Santo (IBAMA, 2015).

Composta por 228 municípios (202 em Minas Gerais e 26 no Espírito Santo), a bacia do rio Doce registrou o efeito direto do desastre em 41 municípios, sendo o

\footnotetext{
${ }^{3}$ Formado pelas barragens de Germano, Fundão e Santarém.
} 
distrito de Bento Rodrigues, pertencente à cidade de Mariana, o mais afetado (ANA, 2016).

Uma das consequências imediatas do incidente foi a suspensão do abastecimento de água nos municípios diretamente afetados, dada a presença de metais e a alteração de outros componentes que contaminam a qualidade da água. Atividades econômicas dependentes do curso das águas, como a pesca, o turismo, dentre outras, também foram prejudicadas, de acordo com o Instituto de Pesquisa Econômica Aplicada (IPEA, 2016).

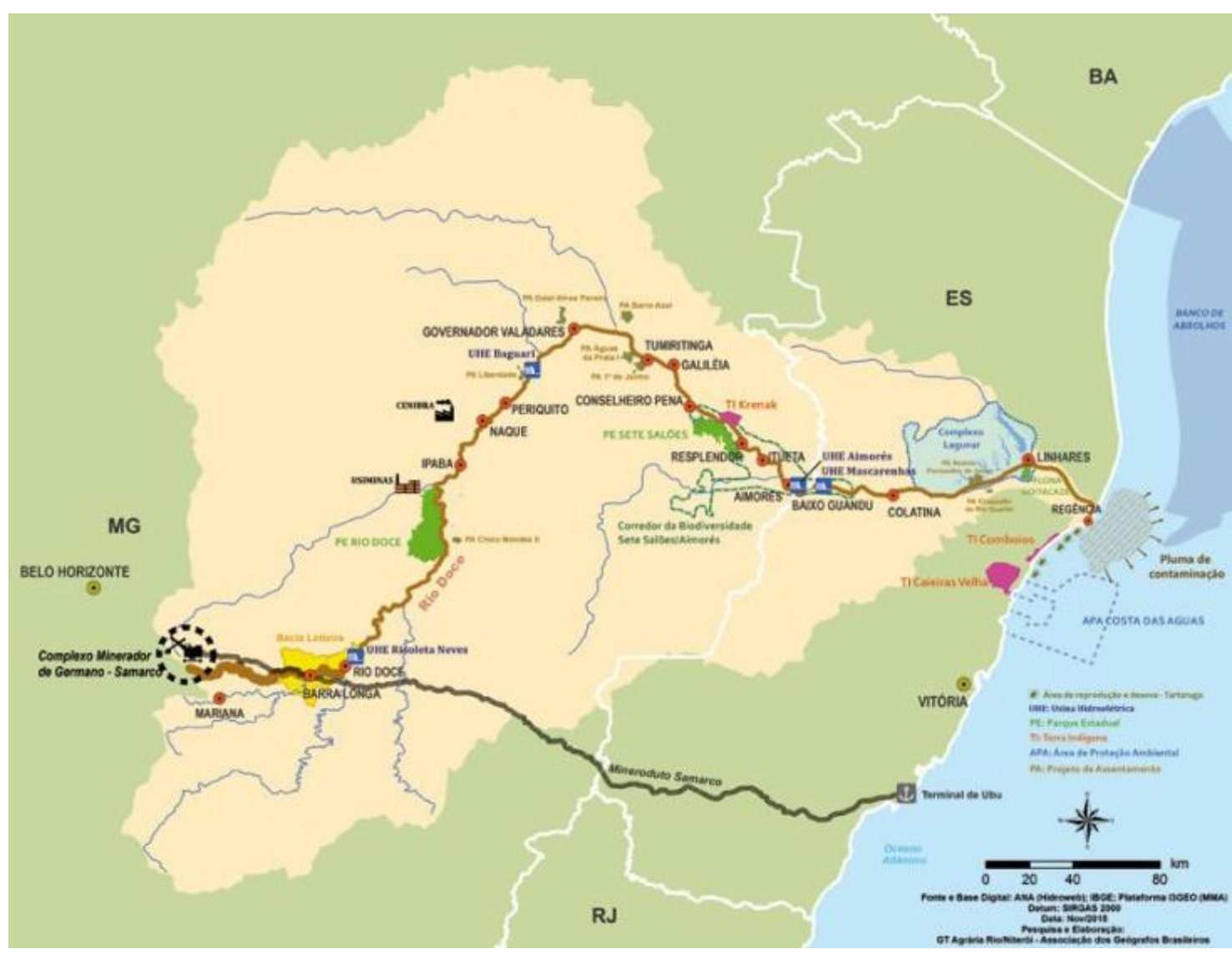

Fonte: Elaborado pela Fiocruz com base nos dados disponibilizados pela ANA (2016).

Figura 1: Percurso dos rejeitos do desastre da barragem de Fundão ao longo da bacia do rio Doce.

Muitas foram as medidas tomadas pelos Governos Estaduais e Federal para o restabelecimento das atividades, sobretudo econômicas, dos municípios afetados pelo desastre. Dentre elas pode-se citar o atendimento emergencial, a antecipação 
dos repasses do "Bolsa-Família" para os indivíduos inscritos no Programa na cidade de Mariana, a liberação de $R \$ 6.220,00$ do FGTS para vítimas atingidas, o abastecimento de água as cidades afetadas, o estabelecimento de multa à mineradora Samarco e a recuperação e o monitoramento do rio Doce (BRASIL, 2016).

\section{Estratégia Empírica}

Para avaliar o impacto do desastre de Mariana no desempenho econômico em Minas Gerais e no Espírito Santo, medido pelas produções industriais e extrativas minerais, é preciso comparar a situação econômica desses Estados depois da ocorrência do desastre com a situação que prevaleceria nesses mesmos Estados, caso não tivesse ocorrido o evento. Evidentemente, o último resultado não é conhecido e há, assim, a necessidade de construir um contrafactual. Em vista disso, é utilizado o controle sintético para a elaboração desse contrafactual.

A técnica do controle sintético busca construir para áreas que foram afetadas pelo desastre tecnológico, Minas Gerais e Espírito Santo, uma trajetória sintética da variável de interesse, neste caso, o desempenho econômico. São usadas covariadas baseadas na literatura de crescimento econômico e na teoria da função de produção agregada (SOLOW, 1956; ROMER, 1986; MANKIW et al., 1992), em que um desastre como o de Mariana é considerado um retrocesso tecnológico exógeno ou um progresso tecnológico exógeno negativo.

Além de levar em conta os efeitos fixos, o método de controle sintético amplia 0 alcance da abordagem de diferenças-em-diferenças considerando também as características não-observadas nos dados variantes no tempo (ABADIE et al., 2010). Ademais, um pressuposto que se deve ter sempre em mente quando se analisa 0 impacto de um tratamento em uma unidade de observação é de que o mesmo não afete o resultado das unidades que compõe o grupo de controle ou de tratamento. Esse pressuposto foi formulado por Rubin (1977), que o denominou "Stable Unit Treatment Value Assumption". No método de controle sintético, a forma de garantir que esse pressuposto seja satisfeito é retirar regiões que podem ter sido afetadas pelo tratamento do grupo de doadores (donor pool). Por isso, foi retirado o Estado do 
Espírito Santo do grupo de doadores para se construir Minas Gerais sintético, assim como foi excluído este último estado na elaboração do Espírito Santo sintético.

Formalmente, seja $X_{1} 0$ vetor de todas as variáveis para as áreas afetadas e $Y_{1}$ o vetor de variáveis de resultado anterior ao desastre. De maneira similar, $X_{0}$ corresponde à matriz cujas colunas são vetores de variáveis de controle para outras áreas que se comportam como potenciais controles e $Y_{0}$ remete à matriz cujas colunas são vetores de suas variáveis de resultados anteriores ao desastre.

$O$ vetor de coluna dos pesos é chamado de $W$, com o peso atribuído à unidade $j$ igual ao $j$-ésimo elemento individual de $W$. Selecionam-se pesos que possam minimizar a seguinte função de distância (ABADIE e GARDEAZABAL, 2003; ABADIE et al., 2010):

$D=\sqrt{\left(X_{1}-X_{0} W\right)^{\prime} V\left(X_{1}-X_{0} W\right)}$

em que $V$ é uma matriz diagonal definida positiva.

Com base nestas informações, o procedimento para criar o controle sintético pode ser elaborado em três passos: o primeiro consiste na escolha da matriz diagonal positiva $V$, e também na resolução dos pesos em função desta matriz $W(V)$; tendo estabelecido $W(V)$, o segundo passo consiste na escolha de um $V$ que minimize o erro de predição quadrático médio durante 0 período pré-desastre: $\operatorname{MSPE}=\left(Y_{1}-\right.$ $\left.Y_{0} W(V)\right)^{\prime}\left(Y_{1}-Y_{0} W(V)\right)$; por fim, repete-se o segundo procedimento até que o MSPE seja o menor possível e, em seguida, encontra-se a matriz de peso de minimização da distância final $W^{*}$.

Definindo-se a matriz $W^{*}$ pelo processo descrito acima, a estruturação da variável de interesse para o tratamento da região sintética corresponderá à média ponderada do valor dessa variável para cada unidade-controle pelo seu respectivo peso ótimo estimado.

Foram coletadas informações mensais para Minas Gerais, Espírito Santo e Estados postulantes a controle (donor pool) entre os anos de 2012 e 2016, o que forneceu uma base de dados com 46 meses pré-desastre e 16 meses pós-desastre. 
Para gerar estimativas consistentes do controle sintético é preciso que o período préevento seja maior quando comparado ao período pós-evento (ABADIE et al., 2010).

O índice de produção física industrial é a variável de resposta, atuando como proxy para o desempenho econômico. Alternativamente, além do índice de produção física industrial geral, também se utilizou o índice de produção física industrial do setor extrativista mineral. ${ }^{4}$

As demais variáveis utilizadas como controle, baseadas na teoria do crescimento econômico, para a construção dos controles sintéticos foram: a quantidade de veículos automotores produtivos relacionados à produção do setor (proxy de capital físico); o estoque de trabalhadores do setor com ensino superior (proxy para capital humano); o estoque de trabalhadores do setor sem ensino superior (trabalho não qualificado); e o fundo de participação estadual (proxy para a atuação do governo). Mais informações como unidades de medida e fonte estão inseridas no Quadro 1.

\begin{tabular}{|c|c|c|c|c|}
\hline Variável & Proxy & Tipo de Variável & Descrição & Fonte \\
\hline $\begin{array}{c}\text { Desempenho } \\
\text { Econômico }\end{array}$ & $Y_{i}$ & Dependente & $\begin{array}{c}\text { Índice da Produção Física Industrial com } \\
\text { base fixa e sem ajuste sazonal (Base: } \\
\text { média de 2012 = 100) (Número-índice) }\end{array}$ & IBGE \\
\hline $\begin{array}{c}\text { Capital } \\
\text { Humano }\end{array}$ & $\mathrm{Hi}$ & Controle & $\begin{array}{c}\text { Estoque de Trabalhadores do Setor } \\
\text { Industrial com Ensino Superior }\end{array}$ & MTE \\
\hline $\begin{array}{c}\text { Trabalho Não } \\
\text { Qualificado }\end{array}$ & $\mathrm{Li}$ & Controle & $\begin{array}{c}\text { Estoque de Trabalhadores do Setor } \\
\text { Industrial sem Ensino Superior }\end{array}$ & MTE \\
\hline Capital Físico & $K_{i}$ & Controle & $\begin{array}{c}\text { Quantidade de veículos automotores } \\
\text { produtivos relacionados ao setor industrial } \\
\text { (caminhonetes, caminhões e caminhões- } \\
\text { tratores) }\end{array}$ & DENATRAN \\
\hline $\begin{array}{c}\text { Fundo de } \\
\text { Participação } \\
\text { Estadual }\end{array}$ & $\mathrm{Gi}$ & Controle & Fundo de Participação dos Estados (R\$) & STN \\
\hline
\end{tabular}

Fonte: Elaborado pelo Autor.

Quadro 1 - Descrição das variáveis utilizadas

A definição dos Estados que participaram do donor poo/ para se fazer o controle sintético tanto para Minas Gerais quanto para o Espírito Santo foi feita com base na disponibilidade de informações a respeito do índice de produção física industrial geral e da produção física extrativista mineral no IBGE. Os Estados que compõem o donor pool para o índice de produção física industrial são: Amazonas (AM), Bahia (BA), Ceará (CE), Goiás (GO), Pará (PA), Paraná (PR), Pernambuco (PE), Rio Grande do Sul (RS), Rio de Janeiro (RJ), Santa Catarina (SC) e São Paulo (SP). Por sua vez, o

\footnotetext{
${ }^{4}$ O IBGE classifica o setor extrativista mineral como a composição das atividades de extração de carvão mineral, de petróleo e serviços correlatos, de minerais metálicos e de minerais não metálicos.
} 
donor pool para o índice de produção física industrial do setor extrativista mineral é composto por: Amazonas (AM), Bahia (BA), Goiás (GO), Rio de Janeiro (RJ) e Pará (PA).

\section{Resultados e Discussão}

Os resultados são apresentados e discutidos em duas subseções. A primeira subseção avalia os impactos do desastre de Mariana sobre o desempenho econômico de Minas Gerais e do Espírito Santo. Por sua vez, a segunda subseção apresenta testes de placebo com o intuito de checar a qualidade dos resultados obtidos na subseção anterior.

\section{Impacto do Desastre no Desempenho Econômico}

A Tabela 1 apresenta os pesos que cada Estado aspirante a doador do controle sintético recebeu para a construção de Minas Gerais e Espírito Santo sintéticos, em dois momentos: na análise geral e na específica do setor extrativista mineral.

Tabela 1: Peso estimado de controle sintético para as variáveis de resultado

\begin{tabular}{ccccc}
\hline \multirow{2}{*}{ Estados } & \multicolumn{3}{c}{ Minas Gerais } & \multicolumn{2}{c}{ Espírito Santo } \\
\cline { 2 - 5 } & PFI & PFIEXT & PFI & PFIEXT \\
\hline Amazonas & 0,00 & 0,00 & 0,22 & 0,33 \\
Pará & 0,00 & 0,00 & 0,52 & 0,37 \\
Ceará & 0,00 & - & 0,00 & - \\
Pernambuco & 0,00 & - & 0,00 & - \\
Bahia & 0,20 & 0,00 & 0,00 & 0,01 \\
Rio de Janeiro & 0,00 & 1,00 & 0,02 & 0,14 \\
São Paulo & 0,19 & - & 0,00 & - \\
Paraná & 0,61 & - & 0,00 & - \\
Santa Catarina & 0,00 & - & 0,00 & - \\
Rio Grande do Sul & 0,00 & - & 0,00 & - \\
Goiás & 0,00 & 0,00 & 0,24 & 0,15 \\
\hline
\end{tabular}

Fonte: Elaborado pelo autor.

Obs: PFI - Produção Física Industrial; PFIEXT - Produção Física Industrial do Setor Extrativista Mineral. 
Três foram os Estados que receberam pesos maiores que zero para Minas Gerais, sendo eles Bahia $(0,20)$, São Paulo $(0,19)$ e Paraná $(0,61)$. Para o Espírito Santo, quatro foram os Estados doadores: Amazonas $(0,22)$, Pará $(0,52)$, Rio de Janeiro $(0,02)$ e Goiás $(0,24)$. No que diz respeito ao segundo experimento, apenas 0 Rio de Janeiro $(1,00)$ apresentou peso positivo para Minas Gerais. Comportamento este diferente do apresentado pelo Espírito Santo, que contou com cinco doadores para o setor extrativista mineral, a saber: Amazonas $(0,33)$, Pará $(0,37)$, Bahia $(0,01)$, Rio de Janeiro $(0,14)$ e Goiás $(0,15)$.

A Figura 2 traça as trajetórias de Minas Gerais e Minas Gerais sintética para a produção industrial e a produção extrativista mineral. Por esta figura, a princípio, constata-se que ambas as séries sintéticas se comportaram como bons contrafactuais de suas respectivas séries verdadeiras, uma vez que previram satisfatoriamente as produções físicas industriais até novembro de 2015, mês em que ocorreu o evento do desastre tecnológico em Mariana. Estes resultados são corroborados pelas raízes dos erros de previsão quadráticos médios (RMSPE) das séries sintéticas em comparação às séries originais. Ao longo do período de pré-tratamento, o valor do RMSPE foi de 3,57 pontos em relação ao índice de produção industrial e 7,50 pontos ao índice de produção industrial extrativista mineral, ambos considerados aceitáveis.

Figura 2: Trajetória da produção física industrial $(\mathrm{PFI})$ e da produção física industrial extrativista mineral (PFIEXT) de MG e MG sintética

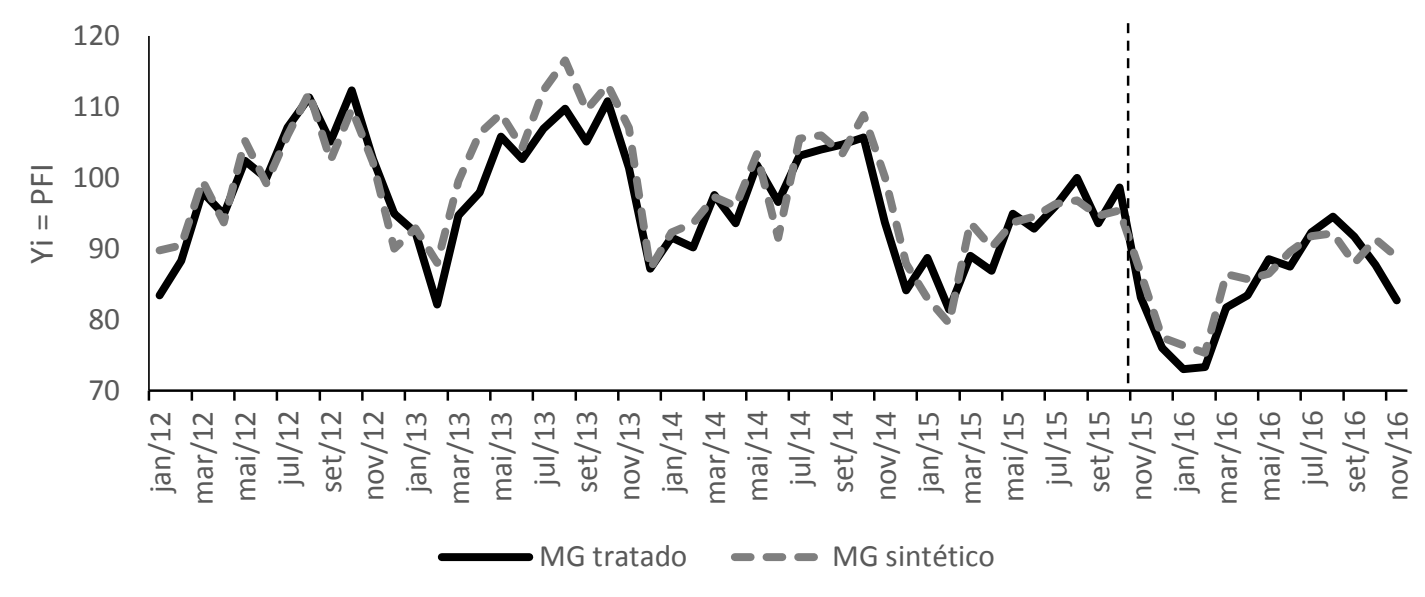




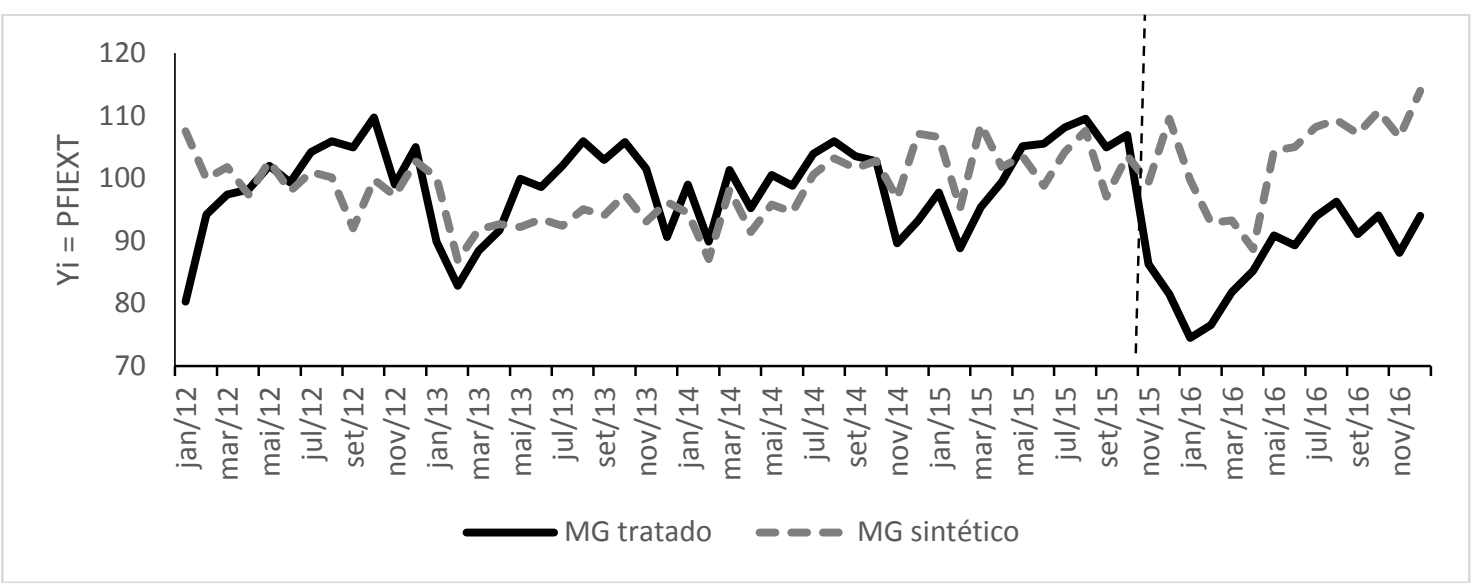

Fonte: Elaborado pelo autor.

Após novembro de 2015 pode-se perceber duas situações distintas em Minas Gerais. Na primeira, a trajetória da série sintética para a produção industrial se mantem acompanhando a sua série original, o que a sustenta como uma boa previsora. Em outras palavras, o fato dela manter-se com boa previsora contradiz a hipótese de que o colapso de Mariana tenha impactado significativamente sobre a produção industrial de Minas Gerais e, com isso, sobre o seu desempenho econômico. Deve-se ter em mente que a região onde ocorreu o desastre, bem como a que margeia a bacia do Rio Doce, no território mineiro, são consideradas de menor dinamismo econômico no Estado. Dessa forma, as demais atividades praticadas em outras regiões de Minas Gerais podem ter minimizado os efeitos médios advindos do desastre tecnológico, em nível estadual.

Em contrapartida, na segunda situação, a trajetória sintética da produção industrial extrativista mineral encontrou-se acima da trajetória da série tratada, em todos os 13 meses após o evento. Este cenário sustenta a ideia de que o impacto do desastre de Mariana atuou de forma negativa e localizada, especificamente no subsetor relacionado.

Similar ao caso mineiro, a Figura 3 delineia as trajetórias do Espírito Santo e do Espírito Santo sintético em razão da produção industrial e da produção indústria extrativista mineral. Para este Estado, percebe-se que as séries sintéticas oscilam um pouco mais em torno das séries reais. A produção física industrial sintética, por exemplo, apresenta distorções positivas ao longo de todo o ano de 2013. A explicação 
para estas distorções pode estar associada ao resultado da produção industrial do Espírito Santo neste mesmo ano. De acordo com o IBGE (2013), entre os 13 Estados considerados para a elaboração deste trabalho (11 doadores e 2 afetados pelo desastre), foi o Espírito Santo aquele que apresentou taxa de crescimento negativa de $6,7 \%$, contra o crescimento da média nacional de $1,2 \%$.

As distorções negativas apresentadas pela produção industrial extrativista mineral sintética podem ser explicadas pelo grande "boom" que o subsetor viveu no ES, em comparação com os demais Estados, a partir de junho de 2014. Foram inauguradas duas plantas industriais: a primeira, pertencente à Samarco, localiza-se no distrito de Ubu, em Anchieta. A segunda, pertencente à Vale, está localizada em Vitória, próxima ao porto de tubarão (IAB, 2014; VALE, 2014).

De maneira geral, por apresentarem algumas distorções que fugiram ao comportamento nacional, os resultados para o Espírito Santo são corroborados pelas raízes dos erros de previsão quadráticos médios (RMSPE) maiores, quando comparados aos mesmos valores de MG. No período de pré-tratamento, observou-se o valor foi de 9,46 pontos para a produção industrial geral e 11,83 para a produção industrial extrativista mineral.

Figura 3: Trajetória da produção física industrial (PFI) e da produção física industrial extrativista mineral (PFIEXT) do ES e ES sintética.

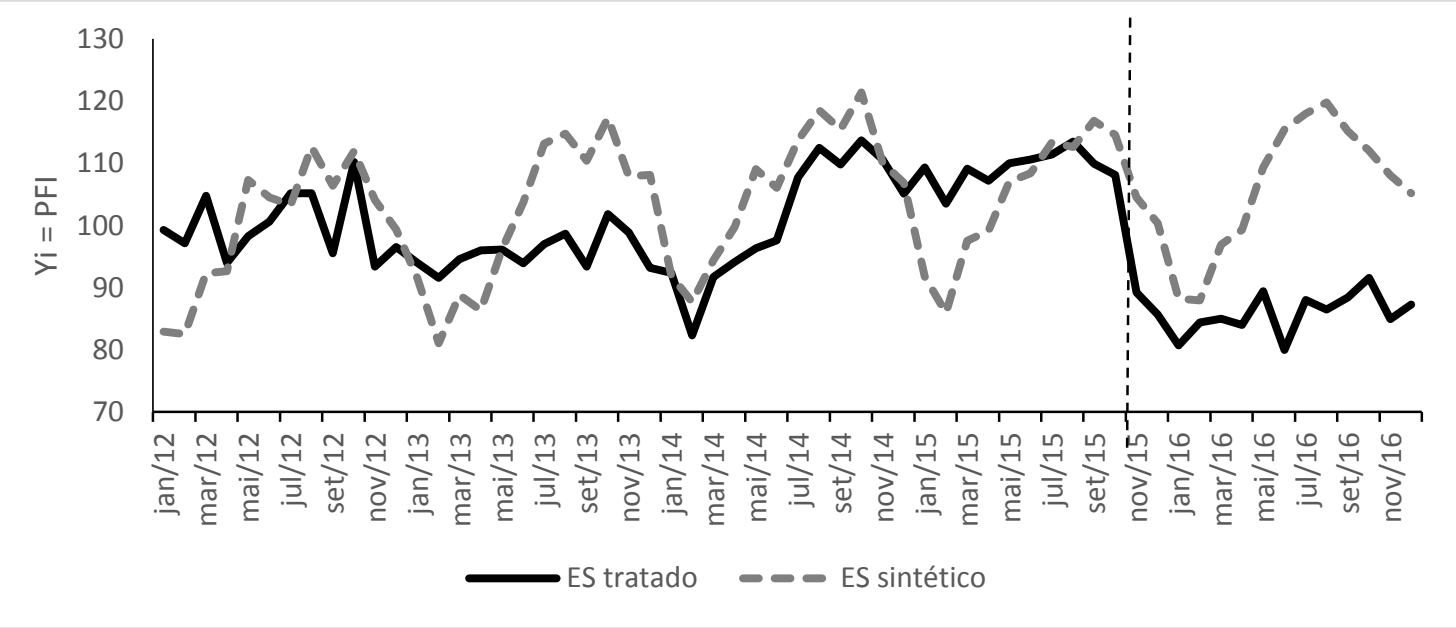




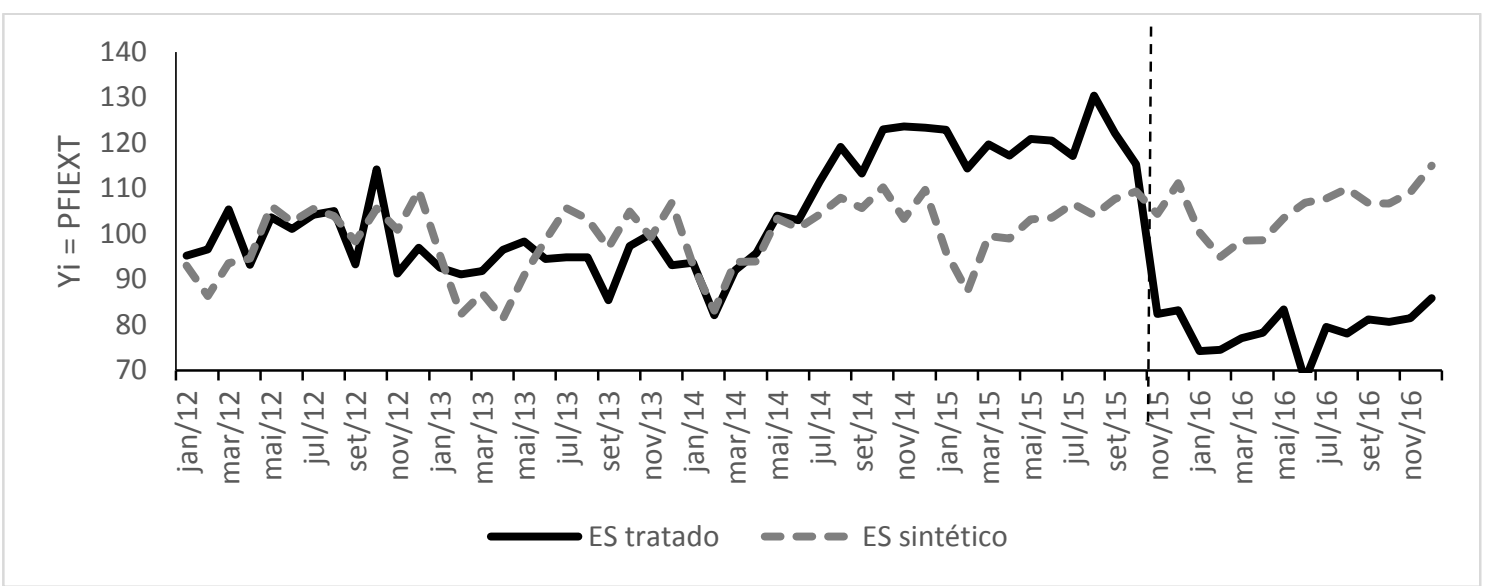

Fonte: Elaborado pelo autor.

Dada a ocorrência do evento, o período pós-desastre apresentou um único cenário para duas as perspectivas no Espírito Santo. Ambas as curvas de produção industrial se estabeleceram acima da trajetória de suas respectivas séries tratadas, por todos os 13 meses seguintes. Desta forma, conclui-se que o impacto do desastre de Mariana atuou de forma negativa na indústria geral e também na indústria de extração mineral no ES.

Além do acompanhamento do impacto do desastre por meio de gráficos e pelas raízes dos erros de previsão quadráticos médios (RMSPE), também é possível calcular a média dos efeitos do desastre na produção industrial e na extrativista mineral. Para tanto, deve-se primeiro calcular a razão entre as respectivas produções industrial reais e sintéticas. Depois disso, computa-se a média para os períodos subsequentes ao desastre (ABADIE et al., 2010; RIBEIRO et al., 2014). Constata-se que a produção industrial geral mensal foi, em média, 18,22\% menor no Espírito Santo, enquanto em Minas Gerais a redução não pode ser considerada significativa. No que tange ao índice da produção industrial extrativa mineral, Minas Gerais apresenta uma produção média mensal inferior em $15,58 \%$, ao passo que o Espírito Santo registra uma redução de $25,01 \% .^{5}$

\section{Testes de Placebo}

Com o objetivo de testar a robustez dos resultados, foram realizados dois testes de placebo tanto para Minas Gerais quanto para o Espírito Santo. No primeiro teste, construíram-se séries sintéticas das produções industrial e extrativista mineral para os

\footnotetext{
${ }^{5}$ As médias para as variáveis pré-tratamento, ou demais variáveis de controle, encontram-se nas Tabelas 2 e 3, em anexo.
} 
Estados escolhidos como possíveis doadores para o controle sintético, com base no mesmo período pré-desastre (anterior a novembro de 2015). Em seguida, calculou-se a diferença entre as trajetórias padrões e sintéticas das variáveis de referência para o conjunto de Estados, para reuni-las em gráficos que contenham a mesma relação para Minas Gerais e Espírito Santo.

Abadie et al. (2010) reforçam que o intuito deste primeiro teste é verificar se a diferença para Minas Gerais e Espírito Santo tratados gera algum comportamento diferente, quando comparado às diferenças dos demais estados não afetados pelo desastre de Mariana. Caso os efeitos de Minas Gerais e Espírito Santo não se localizarem nas extremidades dos seus respectivos gráficos, haverá ausência de significância estatística dos impactos do desastre tecnológico sobre os Estados em questão.

As Figuras 4 e 5 apresentam os resultados deste teste de placebo. $O$ impacto do rompimento da barragem é negativo em todos os meses, no que tange ao subsetor extrativista mineral em Minas Gerais e Espírito Santo, e a indústria geral no Espírito Santo.

Figura 4: Primeiro teste de placebo para a produção física industrial (PFI) de MG e ES.

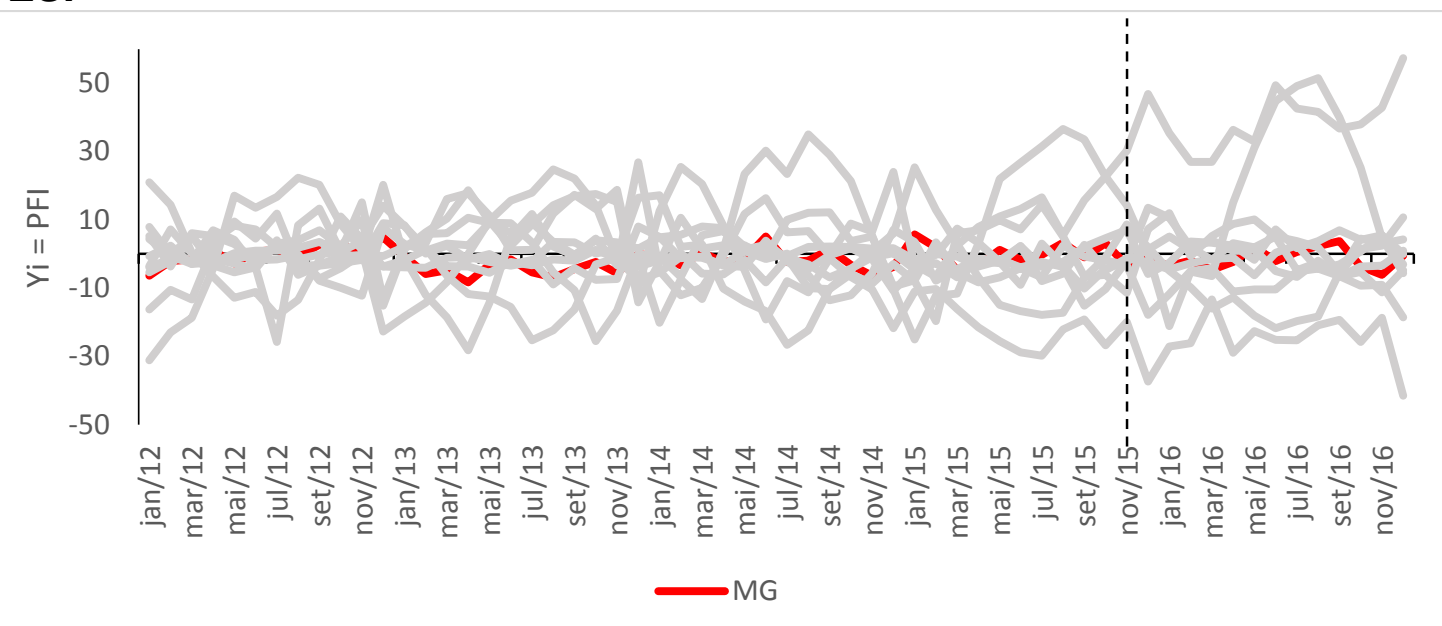




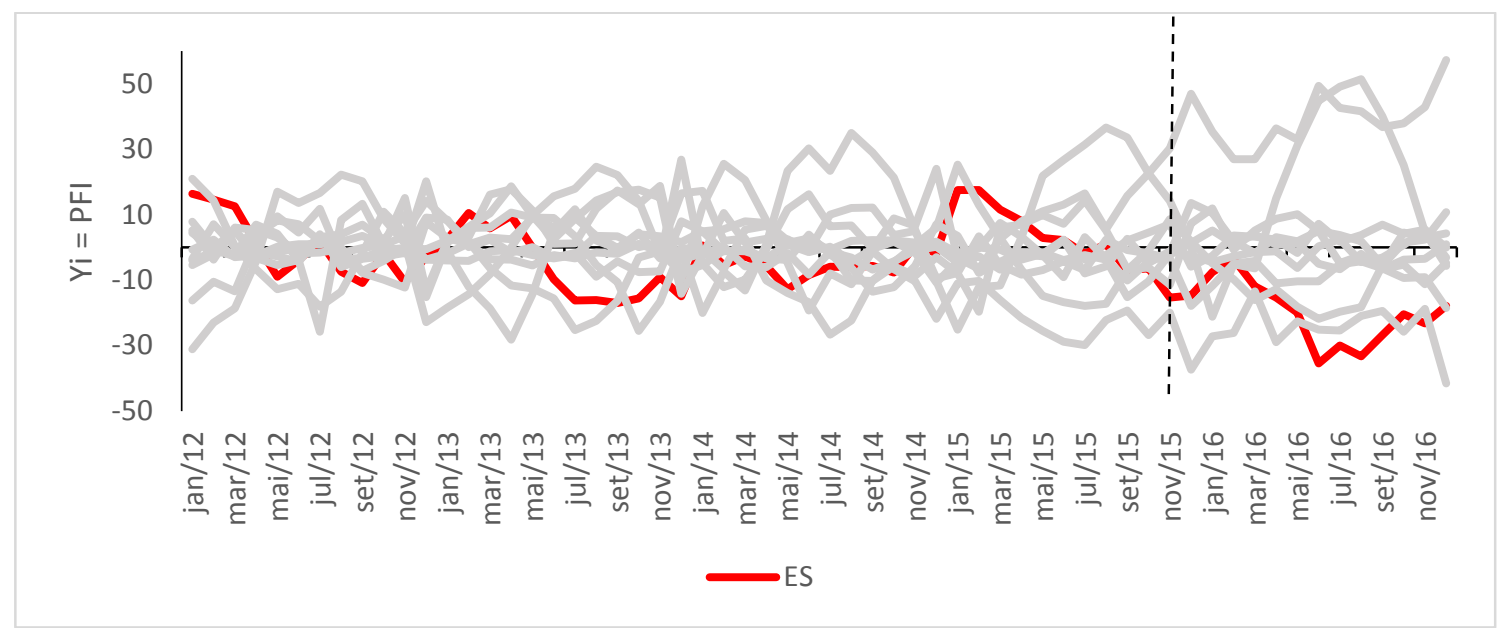

Fonte: Elaborado pelo autor.

Figura 5: Primeiro teste de placebo para a produção física industrial extrativista mineral (PFIEXT) de MG e ES.
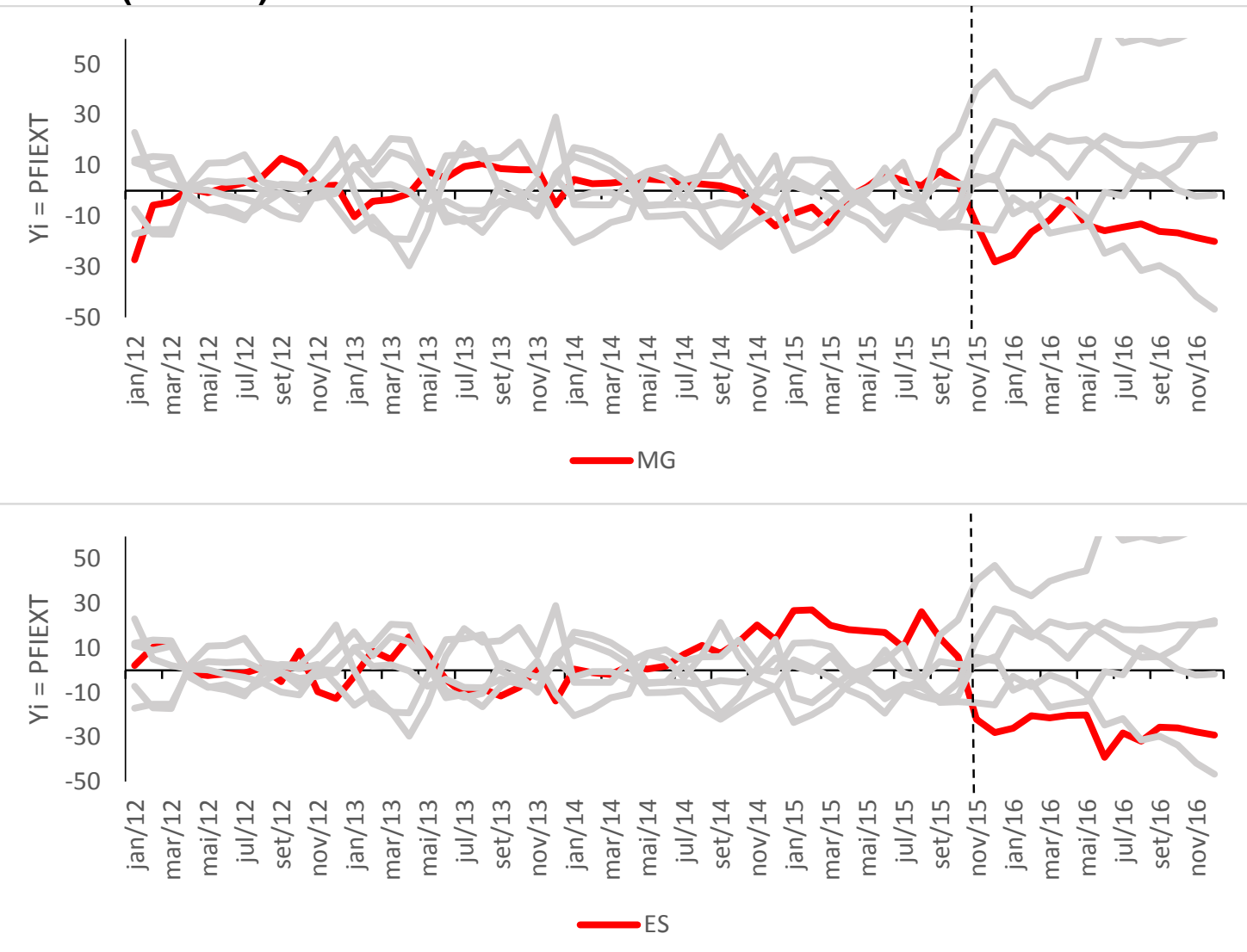

Fonte: Elaborado pelo autor. 
No período pós-tratamento, as séries passam a localizarem-se nas extremidades inferiores de suas distribuições, reforçando o efeito negativo do evento. Para a análise geral da indústria em MG, percebe-se que a série oscila apresentando resultados negativos e positivos. Além do mais, a série mistura-se às demais séries criadas ao longo da distribuição, o que denota ausência de significância estatística (ABADIE et al., 2010). Isto quer dizer que, para Minas Gerais, quando analisado o grande setor da indústria, o resultado dos efeitos do desastre de Mariana não foi estatisticamente significativo.

O segundo teste, por sua vez, é tido como um placebo temporal. A intuição deste teste consiste em mostrar que o efeito encontrado a partir da ação do desastre, em novembro de 2015, não é espúrio. Para tanto, foram elaboradas novas séries sintéticas com períodos de pré-tratamento recuadas em seis meses, ou seja, o corte para avaliação foi deslocado para o mês de maio de 2015. Mesmo com o novo período pré-tratamento, espera-se que não haja alterações no ponto em que as séries sintéticas e tratadas realmente se separaram, dado que a mudança ocorre em novembro de 2015. As trajetórias sintéticas construídas pelas Figuras 6 e 7 acompanharam as trajetórias das séries tratadas, de maneira similar aos resultados das Figuras 2 e 3 . Isto significa que o período pré-desastre recuado no tempo para maio de 2015 não altera os resultados previamente estabelecidos.

\section{Figura 6: Segundo teste de placebo (temporal) para a produção física industrial} (PFI) de MG e ES.

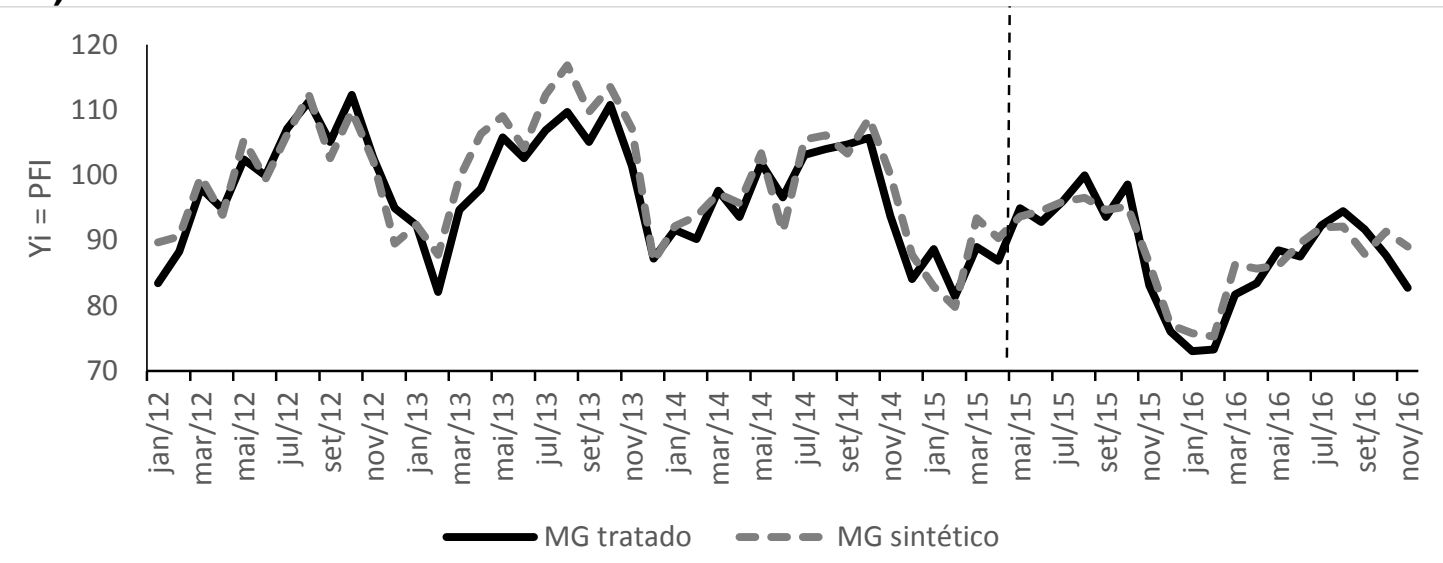




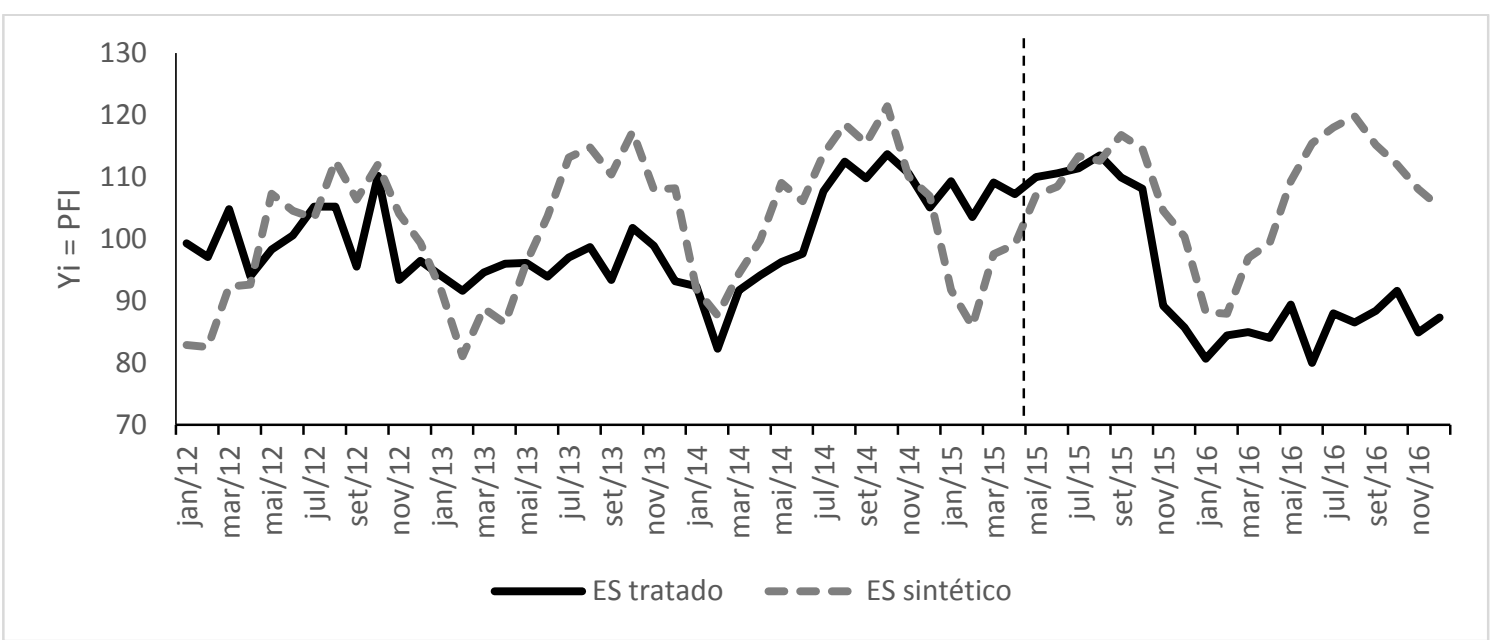

Fonte: Elaborado pelo autor.

Figura 7: Segundo teste de placebo (temporal) para a produção física industrial extrativista mineral (PFIEXT) de MG e ES.
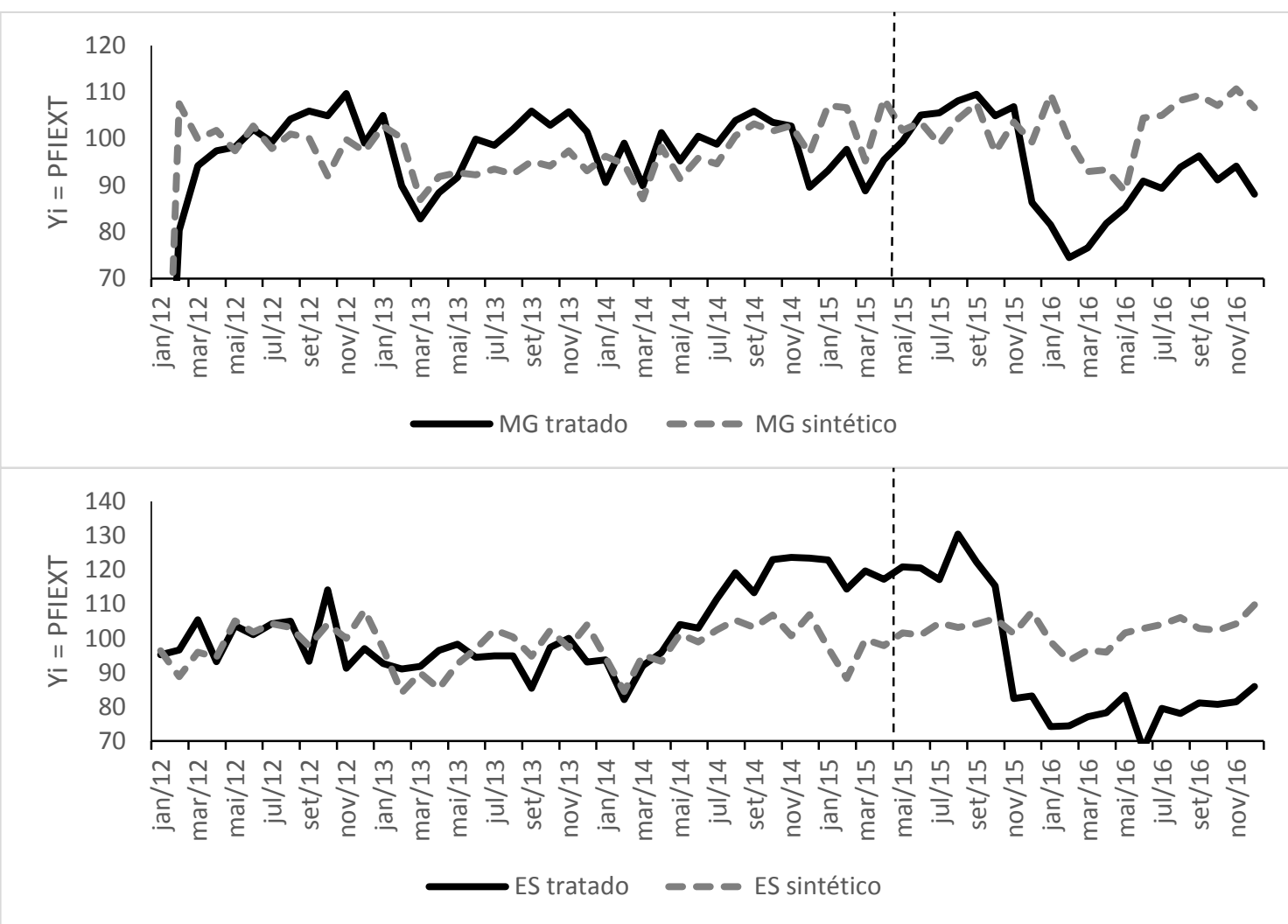

Fonte: Elaborado pelo autor. 


\section{Considerações Finais}

A ocorrência de desastres afeta não apenas as vidas de determinados indivíduos, mas também as economias das regiões atingidas em função da devastação promovida. A literatura registra que a determinação dos efeitos causados e a forma como se reproduzem no tempo não é simples, muito em função da dificuldade em se construir um contrafactual de maneira válida.

Neste trabalho, utilizou-se o método de controle sintético para realizar um estudo do impacto do desastre tecnológico de Mariana nas economias de Minas Gerais e do Espírito Santo. Para tanto, foram comparadas as perspectivas sob a ocorrência do evento contra um contrafactual de manutenção do ciclo econômico, ou seja, sem a ocorrência do desastre, por meio da construção de Minas Gerais e Espírito Santo sintéticos.

Os resultados obtidos mostraram que, no panorama geral, apenas o desempenho econômico do Espírito Santo foi afetado negativamente. No tocante ao setor extrativista mineral, os dois Estados foram afetados, sendo que, no Espírito Santo, o efeito foi maior. A incidência negativa maior no Espírito Santo pode ser dada pela maior dependência deste Estado em relação à participação do setor extrativista mineral em seu produto interno bruto (PIB), aproximadamente quatro vezes maior, quando comparado com o PIB mineiro. A conclusão base do estudo é a de que o Desastre de Mariana impactou mais no Estado do Espírito Santo do que em Minas Gerais.

Para validar os resultados aqui encontrados, também foram feitos testes de placebo que mensuraram a sensibilidade do desastre de Mariana. Os resultados evidenciaram que as séries sintéticas elaboradas se comportaram como bons contrafactuais das séries estaduais tratadas, com exceção da produção industrial para Minas Gerais.

Como agenda de trabalhos futuros, pretende-se estudar o efeito do desastre de Mariana em nível municipal, a partir da disponibilização dos dados pelas agências estatísticas oficiais. A avaliação média dos efeitos em nível estadual, por vezes, pode 
mascarar o impacto em situações específicas, como a dos municípios banhados pela bacia do Rio Doce.

\section{REFERÊNCIAS}

ABADIE, A.; GARDEAZABAL, J. The Economic costs of conflict: A case study of the Basque country. American Economic Review, v. 93, n. 1, p. 113-132, 2003.

ABADIE, A.; DIAMOND, A.; HAINMUELLER, J. Synthetic control methods for comparative case studies: Estimating the effect of California's tobacco control program. Journal of the American Statistical Association, v. 105, n. 490, p. 493-505, 2010.

ANA - Agência Nacional de Águas. Encarte Especial sobre a Bacia do Rio Doce: Rompimento da barragem em Mariana/MG, 2016. Disponível em: <http://arquivos. ana.gov.br/RioDoce/ EncarteRioDoce_22_03_2016v2.pdf>. Acesso em: 01/10/2016.

BLOOM, D. E.; KHANNA, T. The Urban Revolution. Finance \& Development: A Quarterly Magazine of the IMF, v. 44, n. 3, 2007.

BRASIL. Ministério da Integração Nacional - Secretaria Nacional de Defesa Civil. Classificação e Codificação Brasileira de Desastres (Cobrade), 2016. Disponível em: $<$ http://www.mi.gov.br/c/document_library/get_file?uuid=f9cdf8bf-e31e-4902-984 ea859f54dae43\&groupld=10157>. Acesso em: 12/09/2016.

BRASIL. Portal Brasil. Defesa e Segurança. Disponível em: <http://www.brasil.gov.br /defesa-e-seguranca/2015/11/conheca-12-acoes-do-governo-para-enfrentar-os-impa ctosda-tragedia-de-mg-e-es>. Acesso em 03/10/2016.

CAVALLO, E.; GALIANI, S.; NOY, I.; PANTANO, J. Catastrophic Natural Disasters and Economic Growth. Inter-American Development Bank, Working Paper n. 183, 2010.

CBDB - Comitê Brasileiro de Barragens. A história das barragens no Brasil, Séculos XIX, XX e XXI: cinquenta anos do Comitê Brasileiro de Barragens. Rio de Janeiro: CBDB, 2011.

CTPNSB - Comissão Temporária da Política Nacional de Segurança de Barragens. Relatório Final, 2016. Disponível em: <http://legis.senado.leg.br/comissoes/comissa o?1\&codcol=1994. Acesso em: 01/10/2016.

DNPM - Departamento Nacional de Produção Mineral. Cadastro Nacional de Barragens de Mineração, 2016. Disponível em: <http://www.dnpm.gov.br/assuntos/ barragens/cadastro-nacional-de-barragens-de-mineracao>. Acesso em: 02/10/2016.

EM-DAT - Emergency Events Database. The International Disasters Database. Classification, 2016. Disponível em: <http://www.emdat.be/classification>. Acesso em: 10/09/2016. 
EM-DAT - Emergency Events Database. The International Disasters Database. Glossary, 2016. Disponível em: <http://www.emdat.be/glossary/9\#letterd>. Acessado em: 10/09/2016.

GUO, J.; LIU, H.; WU, X.; GU, J.; SONG, S.; TANG, Y. Natural Disasters, Economic Growth and Sustainable Development in China: An Empirical Study Using Provincial Panel Data. Sustainability, v. 7, p. 16.783-16.800, 2015.

HADDAD, E. A.; TEIXEIRA, E. Economic impacts of natural disasters in megacities: The case of floods in São Paulo, Brazil. Habitat International, v. 30, p. 1-8, 2014.

HORWICH, A. Economic Lessos of Kobe Earthquake. Economic Development and Cultural Change, p. 521-542, 2000.

IAB - Instituto Aço Brasil. Notícia Interna, 2014. Disponível em: <http://www.acobrasil .org.br/site2015/noticia_interna.asp?id=11431>. Acesso em 17/10/2017.

IBAMA - Instituto Brasileiro do Meio Ambiente e dos Recursos Naturais Renováveis. Laudo Técnico Preliminar: Impactos ambientais decorrentes do desastre envolvendo o rompimento da barragem de Fundão, em Mariana, Minas Gerais, 2015. Disponível em: <www.ibama.gov.br/phocadownload/noticias_ambientais/laudo_tecnico_preliminar.pdf $>$. Acesso em: 03/10/2016.

IBGE - Instituto Brasileiro de Geografia e Estatística. Agência de Notícias, 2013. Disponível em: <https://agenciadenoticias.ibge.gov.br/agencia-sala-de-imprensa/201 3agencia-de-noticias/releases/14563-asi-em-2013-producao-industrial-cresce-em-11-dos-14locais-pesquisados.html>. Acesso em: 10/10/2017.

IBGE - Instituto Brasileiro de Geografia e Estatística. Países, 2016. Disponível em: <http://paises.ibge.gov.br/\#/pt/pais/brasil/info/sintese>. Acesso em: 18/09/2016.

IPEA - Instituto de Pesquisa Econômica Aplicada. Nota Técnica. Os pescadores da bacia do rio Doce: Subsídios para a mitigação dos impactos socioambientais do desastre da Samarco em Mariana, Minas Gerais, 2016. Disponível em:

$<$ http://www.ipea.gov.br/portal/index.php?option=com_content\&view=article\&id=27809:notatecnica-2016-maio-numero-11-dirur-os-pescadores-da-bacia-do-rio-doce-subs idios-para-amitigacao-dos-impactos-socioambientais-do-desastre-da-samarco-em-mariana-minasgerais\&catid=19 0:dirur\&directory=1 >. Acesso em: 02/10/2016.

KAHN, M. E. The death toll from natural disasters: the role of income, geography, and institutions. Review of Economics and Statistics, v. 87, n. 2, p. 271-284, 2004.

LEISEROWITZ, A. et al. Extreme Weather, Climate \& Preparedness in the American Mind. Yale University and George Mason University. New Haven, CT, Yale Project on Climate Change Communication, 2012.

LOAYZA, N.; OLABERRIA, E.; RIGOLINI, J.; CHRISTIAENSEN, L. Natural Disasters and Growth Going beyond the Averages. The World Bank East Asia and Pacific Social Protection Unit \& Development Research Group. Working Paper, n.4980, 2009. 
MANKIW, N, G.; ROMER, D.; WEIL, D. N. Contribution on the empirics of economic growth. Quarterly Journal of Economics, v. 107, n. 2, p. 407-35, 1992.

MATA-LIMA, H.; et al. Impactos dos Desastres Naturais nos Sistemas Ambiental e Socioeconômico: O que faz a diferença?. Ambiente \& Sociedade, v. 16, n. 3, p. 45-64, 2013.

NOY, I. The macroeconomic consequences of disasters. Journal of Development Economics, v. 88, p. 221-231, 2009.

OKUYAMA, Y. Critical Review of Methodologies on Disaster Impact Estimation. Background paper prepared for the World Bank-U.N. Assessment on the Economics of Disaster Risk Reduction. Niigata, Japan: International University of Japan, 2008.

OKUYAMA, Y.; SAHIN, S. Impact Estimation of Disasters: A Global Aggregate for 1960 to 2007, World Bank Policy Research Working Paper, n. 4963, 2009.

PNDC - Política Nacional de Defesa Civil. Ministério da Integração Nacional, Brasília, 2007. Disponível em: <http://www.mi.gov.br/c/documentlibrary/getfile?uuid=6aa2e891-98f648a6-8f47- 147552c57f94\&groupld=10157>. Acesso em: 14/09/2016.

RIBEIRO, F. G.; STEIN, G.; CARRARO, A.; RAMOS, P. L. O Impacto Econômico dos Desastres Naturais: O caso das chuvas de 2008 em Santa Catarina. Planejamento e Políticas Públicas, n.43, p.299-322, 2014.

ROMER, P. M. Increasing Returns and Long-Run Growth. Journal of Political Economy, v.94, n.5, p.1002-37, 1986.

RUBIN, D. Assignment to a Treatment group on the basis of a Covariate. Journal of Educational Statistics, n. 2, p.1-26, 1977.

SELUCK, F.; YELDAN, E. On the macroeconomic impact of the august 1999 earthquake in Turky: a first assessment. Applied Economic Letters, v. 8, p. 483- 488, 2001.

SIMONATO, T. C. Projeção dos impactos econômicos regionais do desastre de Mariana-MG. 2017. 182 f. Dissertação (Mestrado em Economia) - Universidade Federal de Minas Gerais, Centro de Desenvolvimento e Planejamento Regional, Belo Horizonte, 2017.

SOLOW, R. A contribution to the theory of economic growth. The Quartely Journal of Economics, v.70, n.1, p.65-94, 1956.

VALE. Sobre a VALE, 2014. Disponível em: <http://www.vale.com/brasil/PT/aboutva le/news/Paginas/vale-investiu-mais-1-bilhao-espirito-santo-2014.aspx>. Acesso em: 17/10/2017.

WORLD BANK; UNITED NATIONS. Natural hazards, unnatural disasters: the economics of effective prevention. Washington, DC: The International Bank for Reconstruction and Development/The World Bank, 2010. 
ANEXO:

Tabela 2: Média das variáveis pré-tratamento para Minas Gerais e Minas Gerais sintética

\begin{tabular}{ccccc}
\hline Variáveis Pré- & \multicolumn{2}{c}{ PFI } & \multicolumn{2}{c}{ PFIEXT } \\
\cline { 2 - 5 } Tratamento & Tratado & Sintético & Tratado & Sintético \\
\hline $\mathrm{K}_{\mathrm{i}}$ & 1.024 .157 & 1.023 .391 & 1.026 .113 & $419.400,70$ \\
$\mathrm{G}_{\mathrm{i}}$ & 205.000 .000 & 177.000 .000 & 205.000 .000 & 70.200 .000 \\
$\mathrm{H}_{\mathrm{i}}$ & $64.043,83$ & $100.254,70$ & $6.898,61$ & $16.163,13$ \\
$\mathrm{~L}_{\mathrm{i}}$ & $857.288,20$ & $942.208,40$ & $50.683,47$ & $30.384,11$ \\
\hline
\end{tabular}

Fonte: Elaborado pelo autor.

Obs: PFI - Produção Física Industrial; PFIEXT - Produção Física Industrial do Setor Extrativista Mineral; $K_{i}$ - Capital Físico; $G_{i}$ - Fundo de Participação Estadual; $H_{i}$ - Capital Humano; $L_{i}$ - Trabalho não Qualificado.

Tabela 3: Média das variáveis pré-tratamento para Espírito Santo e Espírito Santo sintético

\begin{tabular}{ccccc}
\hline \multirow{2}{*}{ Variáveis Pré-Tratamento } & \multicolumn{2}{c}{ PFI } & \multicolumn{2}{c}{ PFIEXT } \\
\cline { 2 - 5 } & Tratado & Sintético & Tratado & Sintético \\
\hline $\mathrm{K}_{\mathrm{i}}$ & $207.696,80$ & $207.043,90$ & $209.689,80$ & $209.718,00$ \\
$\mathrm{G}_{\mathrm{i}}$ & 68.900 .000 & 207.000 .000 & 68.900 .000 & 177.000 .000 \\
$\mathrm{H}_{\mathrm{i}}$ & $11.230,28$ & $11.059,29$ & $2.573,61$ & $3.511,57$ \\
$\mathrm{~L}_{\mathrm{i}}$ & $138.575,70$ & $149.352,30$ & $11.674,30$ & $11.687,57$ \\
\hline
\end{tabular}

Fonte: Elaborado pelo autor.

Obs: PFI - Produção Física Industrial; PFIEXT - Produção Física Industrial do Setor Extrativista Mineral; $\mathrm{K}_{\mathrm{i}}$ - Capital Físico; $\mathrm{G}_{i}$ - Fundo de Participação Estadual; $\mathrm{H}_{\mathrm{i}}$ - Capital Humano; $\mathrm{L}_{i}$ - Trabalho não Qualificado.

\section{NOTAS DE AUTOR}

\section{CONTRIBUIÇÃO DE AUTORIA}

Lucas Siqueira de Castro - Concepção e elaboração do manuscrito. Coleta de dados. Análise de dados. Elaboração do manuscrito. Revisão e aprovação da versão final do trabalho

Eduardo Almeida - Concepção e elaboração do manuscrito. Participação ativa da discussão dos resultados. Revisão e aprovação da versão final do trabalho.

\section{FINANCIAMENTO}

PNPD/CAPES - Universidade Federal de Juiz de Fora.

Fundação de Amparo à Pesquisa do Estado de Minas Gerais (Fapemig) e Conselho Nacional de Desenvolvimento Científico e Tecnológico (CNPq).

\section{CONSENTIMENTO DE USO DE IMAGEM}

Não se aplica.

\section{APROVAÇÃO DE COMITÊ DE ÉTICA EM PESQUISA}

Não se aplica.

CONFLITO DE INTERESSES

Não se aplica. 
LICENÇA DE USO

Este artigo está licenciado sob a Licença Creative Commons CC-BY. Com essa licença você pode compartilhar, adaptar, criar para qualquer fim, desde que atribua a autoria da obra.

\section{HISTÓRICO}

Recebido em: 10-07-2018

Aprovado em: 24-09-2018 